\title{
An Efficient Preparation Method of ZnO Nanoparticles toward Enhanced Photocatalytic and Antibacterial Activity ${ }^{\dagger}$
}

\author{
Md. Abu Hanif ${ }^{1}$, Jeasmin Akter ${ }^{2}$, Md. Akherul Islam ${ }^{1}$, Kamal Prasad Sapkota ${ }^{2}$, Hafiz Abbas ${ }^{3}$ and \\ Jae Ryang Hahn 1,2,4,* \\ 1 Department of Bioactive Material Sciences, Jeonbuk National University, Jeonju 54896, Korea; \\ hanif4572@gmail.com (M.A.H.); akherulraju@gmail.com (M.A.I.) \\ 2 Department of Chemistry, Jeonbuk National University, Jeonju 54896, Korea; tina44445@gmail.com (J.A.); \\ mychemistry2037@gmail.com (K.P.S.) \\ 3 Department of Nanoscience and Technology, Research Institute of Physics and Chemistry, Jeonbuk National \\ University, Jeonju 54896, Korea; ga32949@gmail.com \\ 4 Textile Engineering, Chemistry and Science, North Carolina State University, 2401 Research Dr., Raleigh, \\ NC 27695-8301, USA \\ * Correspondence: jrhahn@jbnu.ac.kr \\ + Presented at the 2nd International Online-Conference on Nanomaterials, 15-30 November 2020; Available \\ online: https://iocn2020.sciforum.net/.
}

Citation: Hanif, M.A.; Akter, J.; Islam, M.A; Sapkota, K.P.; Abbas, H.; Hahn, J.R. An Efficient Preparation Method of $\mathrm{ZnO}$ Nanoparticles toward Enhanced Photocatalytic and Antibacterial Activity. Mater. Proc. 2021, 4, 41. https://doi.org/10.3390/ IOCN2020-07972

Academic Editors: Ana María Díez-Pascual, Antonio Di Bartolomeo and Guanying Chen

Published: 12 November 2020

Publisher's Note: MDPI stays neutral with regard to jurisdictional claims in published maps and institutional affiliations.

Copyright: (C) 2020 by the authors. Licensee MDPI, Basel, Switzerland. This article is an open access article distributed under the terms and conditions of the Creative Commons Attribution (CC BY) license (http://creativecommons.org/licenses /by/4.0/).
Abstract: $\mathrm{ZnO}$ is an attractive semiconductor material due to its potential application in various fields such as solar cells, antibiotics, gas sensors, organic pollutant degradation, etc. For this purpose, researchers are trying to synthesize $\mathrm{ZnO}$ by using different methods such as sol-gel techniques, electrodeposition, mechanochemical and sonochemical methods, and chemical vapor deposition. However, it is still necessary to improve an economical method for synthesizing $\mathrm{ZnO}$. In the present study, we synthesized $\mathrm{ZnO}$ nanoparticles (ZnO-NPs) by a thermal method. The process is environmentally safer than other methods because it does not involve more chemicals or a catalyst, acid, or base source. We used methylene blue for photocatalytic activity tests and Escherichia coli for antibacterial activity tests. The results found an outstanding degradation percentage ( $\sim 99 \%$ ) for the photocatalytic experiment. Moreover, the antibacterial activity was tested at different concentrations, and the minimum inhibitory concentration (MIC) of the ZnO-NPs was 30 50 $\mu \mathrm{g} / \mathrm{mL}$. Our synthesized $\mathrm{ZnO}-\mathrm{NPs}$ were found to be more effective than previously described $\mathrm{ZnO}-\mathrm{NPs}$ prepared via other methods.

Keywords: ZnO Nanoparticles; Photocatalytic Activity; Antibacterial Activity

Supplementary Materials: The following are available online at https:/www.mdpi.com/article/ 10.3390/IOCN2020-07972. 